\title{
Advanced Medical Devices for Preparation and Administration of Chemotherapeutic Agents: Results from a Multi-Dimensional Evaluation
}

This article was published in the following Dove Press journal: ClinicoEconomics and Outcomes Research

\author{
Lucrezia Ferrario (1) \\ Fabrizio Schettini' \\ Elisabetta Garagiola' \\ Adriana Cecchi ${ }^{2}$ \\ Lucia Lugoboni ${ }^{3}$ \\ Paolo Serra ${ }^{4}$ \\ Emanuele Porazzi ${ }^{1}$ \\ Emanuela Foglia (D) \\ 'Carlo Cattaneo - LIUC University and \\ LIUC Business School, Castellanza, Italy; \\ ${ }^{2}$ ARCS - Azienda Regionale di \\ Coordinamento per la Salute, Udine, \\ Italy; ${ }^{3}$ Bee Care, Lugano, Switzerland; \\ ${ }^{4}$ Brotzu Hospital, Cagliari, Italy
}

Correspondence: Lucrezia Ferrario Carlo Cattaneo - LIUC University and LIUC Business School, Corso Matteotti 22, Castellanza, VA 21053, Italy

$\mathrm{Tel}+39033 \quad 1572504$

$\mathrm{Fax}+390331572513$

Email Iferrario@liuc.it
Purpose: To evaluate the incremental benefits concerning the implementation of closedsystem medical devices for the preparation and administration of chemotherapy agents (integrated or not with traceable workflow), within an Italian clinical practice, in which the use of such technologies is not standardized.

Methodology: Four Scenarios, implying different levels of technologies introduction, were analyzed, based on the presence and/or absence of closed systems and traceable workflow, in the preparation and in the administration phase. A literature review was conducted, in order to retrieve efficacy and safety measures. Economic and organizational benefits, assuming a hospitals perspective, were assessed by means of health-economics tools, considering 27,660 ( \pm 695.86$)$ drugs on average prepared, on an annual basis, by 12 hospitals involved. The typology of medical devices and other devices/equipment used, the human resources involved, and the time spent for the preparation and administration phases were collected.

Results: Literature stated that the introduction of advanced technologies (CSTDs in the preparation phase, closed-system in the administration phase, both integrated by a traceable workflow) could: i) decrease surface contamination $(12.24 \%$ vs $26.39 \%, P<0.001)$ and ii) improve the capability to identify dosage errors $(7 \%$ vs $0.096 \%, P<0.05)$. The above technologies presented the best trade-off between cost sustained and efficacy gained. Despite marginal investments (ranging from $+1 \%$ to $+6 \%$ ) being required for their acquisition, an organizational saving equal to more than 1,000 working hours emerged, which could be spent on other hospital activities.

Conclusion: The implementation of closed systems, integrated with a traceable workflow grounding on gravimetric control, may be considered a valid technological alternative within the investigated setting. The marginal incremental costs could be absorbed already in the first year after their introduction, in particular, because of the potential time saving in using closed systems in both the preparation and administration phases, demonstrating the sustainability and feasibility of such advanced technologies.

Keywords: closed-system medical device, chemotherapy agents, safety, economic evaluation, HTA, organisational benefits

\section{Introduction}

In the European Union, 3.7 million citizens receive the devasting diagnosis of cancer every year, leading to 1.9 million deaths each year. ${ }^{1}$ However, $40 \%$ of cancer cases could be preventable by means of screening programs, which are the most effective way of reducing the burden of cancer, even if only $3 \%$ of the healthcare budget is spent on prevention activities across the EU. 
In general, prevention measures include both the actions performed at medical and individual level (in terms of lifestyle choices), as well as reducing environmental risk factors. This last aspect is very important in the management and care of cancer diseases, whose most utilized treatment is the infusion of chemotherapeutic drugs. ${ }^{2}$ Thus, scientific studies have demonstrated that hospital workers who handle cytotoxic drugs are 3-times more likely to develop malignancy, and that nurses exposed to cytotoxic drugs are twice as likely to miscarry. ${ }^{3-5}$ This is particularly important in light of the existing Carcinogens and Mutagens Directive 2004/ 37/EC (CMD) adopted in Italy by Law $81 / 2008$, devoted to the preparation, administration, and disposal of hazardous drugs to prevent exposure, and could have a positive impact both for patients and healthcare personnel. ${ }^{6}$

For this reason, closed-system drug transfer devices (CSTDs) have become increasingly important with regard to both the preparation and administration of drugs, to be utilized together with other handling practices and protective devices, that should be used in the manipulation of chemotherapeutic drugs (protective clothing, gloves, and biological safety cabinets), thus improving the overall safety at organizational level. ${ }^{6}$ According to the US National Institute for Occupational Safety and Health, CSTD represents a drug transfer device, which mechanically prohibits the transfer of environmental contaminants into a system, and the escape of hazardous drug or vapor concentrations outside the system. ${ }^{7}$ The literature provides evidence in support of their safety profile, with regard to the exposure to antineoplastic drugs in a hospital working environment, ${ }^{8-11}$ with important advantages for pharmacists and nurses. Furthermore, the implementation of an adequate CSTD in the preparation phase could help ensure the sterility of vialed medication for at least 7 days, ${ }^{12-14}$ reducing waste and improving the overall environmental safety. In addition, in clinical practice, it is important to use closed systems also in the administration phase, to ensure that neither the healthcare professional nor the patients are at risk of contamination.

In particular, these systems are equipped with a connector able to protect the operator, and the patient during the drug administration phase, with direct connections between bags/syringes containing the drug and the catheter.

In this virtuous cycle, an innovative technology, comprised of a traceable workflow using gravimetric control, could be inserted and implemented in the preparation phase. This could help to improve the medication safety, and thus reduce potential errors in dosage drugs, associated with visual inspections, and increment the environmental safety for clinicians, technicians, and nurses working in the compounding unit. ${ }^{15-17}$

Furthermore, according to the American Pharmacists Association (2016), ensuring the right dose of the right drug reaches the right patient at the right time by the right route is the minimum standard by which a pharmacist reviews every medication order for every patient, ${ }^{18}$ suggesting that the introduction of CSTD and traceable workflow with gravimetric control could have a direct impact also on patient safety.

According to the above, the use of closed systems (integrated or not with a traceable and gravimetric workflow) would achieve a 2-fold objective, related to prevent the impact of hazardous drugs for healthcare workers, and, at the same time, increase the level of safety in the management of oncologic patients.

Exploring the potential improvements in the management of primary prevention at hospital level is becoming an urgent priority, thus increasing the chance of better health outcomes for all the individuals involved in cancer care and evaluating the economic feasibility of adopting the abovementioned medical devices. This activity is particularly relevant for the Italian setting where a low level of recommendations adherence is reported, in terms of a standardized approach in the adoption of closed systems. ${ }^{19}$

According to these premises, the study aims at assessing the incremental benefits of implementing closed-system medical devices into the preparation and administration phases of chemotherapy agents (integrated or not with traceable workflow), within an Italian situation in which the use of such medical devices is not standardized. In particular, the efficacy and safety profiles as well as the economic and organizational advantages will be deeply investigated. Due to the fact that advanced technologies are always related to higher costs, it is important to understand if, in order to guarantee greater safety and efficacy for healthcare professionals, an additional investment is needed, or if the technological switch would generate economic and organizational savings, to be further invested in prevention activities.

\section{Methods}

To achieve the aforementioned objective, a health technology assessment (HTA) approach grounded on the dimensions of the AdHoPHTA framework was implemented, assuming the hospital point of view, thus being the most acknowledged model to be used at hospital level, for taking managerial decisions. ${ }^{20}$ Among the aspects 
proposed by the AdHopHTA framework, in the proposed manuscript the following dimensions were deeply investigated, because of their major relevance in the hospital setting: i) health problems and current use of the technologies; ii) description and technical characteristic of the investigated technologies, by analysing their potential benefits; iii) safety profile of the investigated technologies, in terms of their capability to reduce the hazardous drugs risk for healthcare professionals; iv) efficacy profile, in terms of capability of the technology to reduce dosage errors; v) economic and financial dimension, for understanding the impact of the technologies on the hospital internal processes, as well as their economic sustainability and affordability; and vi) organizational impact, in terms of the definition of the time spent by the healthcare professionals for preparing and administering the drugs, thus identifying the potential working hours release.

These aspects were deployed considering a literature review for the collection of safety and efficacy indicators and health economics tools, that are useful for the economic evaluation of clinical pathways and for conducting budget impact analyses, as well as for assessing the organizational advantages in terms of time savings.

It should be noted that the economic and organizational analyses focused on the average number of prepared and administered doses considering a 12-month time horizon in a medium-size hospital, that is equal on average to 27,660 $( \pm 695.86 \mathrm{SE})$ drugs, as observed in the different centers involved.

Specifically, during the year 2019, an analysis of the medical devices used in 12 Italian hospitals was conducted, in terms of utilization of closed or open systems for preparing and administering chemotherapeutic drugs, as well as the presence of a specific traceable workflow grounding on gravimetric control in the preparation phase.

According to the real-life technological level of the hospitals involved, the analysis compared the following four scenarios.

- Scenario $0 \rightarrow$ absence of CSTD in the preparation phase, absence of a closed system in the administration phase, and absence of traceable workflow.

- Scenario $1 \rightarrow$ presence of CSTD in the preparation phase, absence of a closed system in the administration phase, and absence of traceable workflow.

- Scenario $2 \rightarrow$ presence of CSTD in the preparation phase, presence of a closed system in the administration phase, and absence of traceable workflow.
- Scenario $3 \rightarrow$ presence of CSTD in the preparation phase, presence of a closed system in the administration phase, and presence of traceable workflow.

Besides the technological level, real-life data derived from hospitals considered the time spent for each drugs' preparation and administration, as well as the human resources involved, and all the consumables used for the entire activity.

\section{Assessment of the HTA Dimensions Literature Review}

The "PICO" (Patient, Intervention, Comparator, Outcome) approach was identified, for undertaking literature review: $\mathrm{P}$ - adult oncologic patients treated with chemotherapeutic agents; I - presence of CSTD in the preparation phase, presence of a closed-system in the administration phase, and presence of traceable workflow (representing the Scenario 3); C - absence of CSTD in the preparation phase, absence of a closed-system in the administration phase, and absence of traceable workflow (representing Scenario 0); presence of CSTD in the preparation phase, absence of a closed-system in the administration phase, and absence of traceable workflow (representing Scenario 1); presence of CSTD in the preparation phase, presence of a closed-system in the administration phase, and absence of traceable workflow (representing the Scenario 2); O occurrence rate of surfaces and healthcare professionals' contamination and identification errors.

In accordance with the above PICO, a literature review was conducted in order to understand the state of art of the investigated topic. In this view, the search strategy included the following keywords: "closed-system transfer device", "antineoplastic drug", "chemotherapy preparation", "chemotherapy administration", "gravimetric control", "dosage error", "identification error", "healthcare professionals exposure", and "contamination surface". Pubmed/Medline, Embase, and Cochrane Databases were used.

After the identification of the papers meeting the proposed PICO, the risk of bias was evaluated by means of both the ROBIN-I tool, and the Newcastle-Ottawa Scale, in order to define the quality of the results. ${ }^{21,22}$ Literature was then used, in order to retrieve evidence-based information regarding the safety and the efficacy profiles of the different medical devices used in the clinical practice for the preparation and administration of chemotherapeutic agents. 


\section{Economic and Organizational Dimension}

To correctly assess the economic and financial aspects of clinical practice, it was necessary to analyze and determine the costs of the clinical pathway, by focusing on the drug preparation and administration phases, over a period of 12 months, assuming the hospital perspective. It was also necessary to determine the cost-effectiveness of the alternatives studied, to evaluate the overall economic and financial implications of the new different devices.

At first, an activity-based costing (ABC) was used to define all the costs related to the preparation and administration of chemotherapeutic agents in hospitals, by mapping the standard processes performed in the clinical practice. ${ }^{23}$

It should be noted here that the economic evaluation of the process did not consider the definition of any advantages related to the management of drug residual, that could also generate greater economic benefits, demonstrating the fact that the here proposed economic evaluation was implemented with a conservative approach. The following items of healthcare expenditure were analyzed, without considering the drug's cost: i) human resources; ii) consumables and equipment; iii) medical devices; iv) traceable workflow (whose economic component has been calculated conservatively, considering the legal depreciation of the asset); and v) general costs (representing $15 \%$ of the total cost). All the above items of healthcare expenditure were accordingly valorised considering the medical devices acquisition costs, referring to the year 2019, and valid also for the year 2020 .

The economic evaluation of the process was then integrated with both a cost-efficacy analysis (CEA) and a budget impact analysis (BIA), always taking into consideration the hospital perspective. Whereas a CEA evaluates both the costs and outcomes of alternative technologies over a specified time horizon, to estimate their economic efficiency, a BIA is based on their affordability. On the one hand, the costefficacy value was assessed in order to understand the panel of technologies having the better cost (information derived from the economic evaluation of the process, by means of the above-mentioned $\mathrm{ABC}$ analysis) and efficacy (information derived from literature review, in terms of identification error rate) ratio. On the other hand, to complete the economic and financial dimension, a budget impact analysis (BIA) was conducted to predict the economic and financial consequences of adopting a new technology within a healthcare organization, with finite resources. ${ }^{24,25}$ Thus, the BIA was developed considering 27,660 drugs ( $\pm 695.86 \mathrm{SE}$ ) that were prepared and administered on average, within the hospitals involved, over a period of 12 months, thus being consistent with the hospital budget timeframe.

Besides the economic and financial analysis related to the different scenarios, the organizational impact was also detected, in terms of time released for the preparation and administration of therapies.

\section{A Focus on Statistical Methods}

Study data were first analyzed, considering descriptive statistics. Differences between Scenarios were evaluated, according to a significance level lower than 0.05 ( $P$-value), thus using the two-way ANOVA. This specific statistical test was conducted to elicit the existence of statistically significant differences among groups, with regard to the economic evaluation of the single process as well as the time spent for preparing and administering a single dose, considering the four different scenarios of interest.

With regard to the economic and the organizational dimensions, both a scenario and a sensitivity analysis were conducted, in order to verify the robustness of the results. At first, a scenario analysis was performed, on the basis of the potential technological replacement rate (equal to $100 \%$ or $75 \%$, respectively), for the analysis of the budget and the organizational impacts.

Secondly, Bayesian statistics was applied. ${ }^{26,27}$ Beta and Gamma distributions were accordingly developed, in order to verify the robustness of the results in the presence of uncertainty factors (efficacy, entire process costs, process costs without human resources costs, organizational time saving). In particular, Beta and Gamma distributions were developed according to average values of the above factors and their related standard deviation, thus performing a Monte-Carlo Simulation. Thus, the probability to have: i) any efficacy average value of the Beta distribution of Scenario 3, higher with respect to the others; ii) any cost average value (with the inclusion or the exclusion of the human resources costs) of the Gamma distribution of Scenario 3, lower with respect to the others; and iii) any average organizational time saving of the Gamma distribution of Scenario 3, lower with respect to the others, was evaluated.

\section{Results}

\section{Results from Literature Review}

Results from the literature review are synthesized in the Prisma Flow Chart (Figure 1): ${ }^{28}$ out of the 1,262 records found, only eight met the inclusion criteria defined in the PICO and focused on a comparative assessment of the 


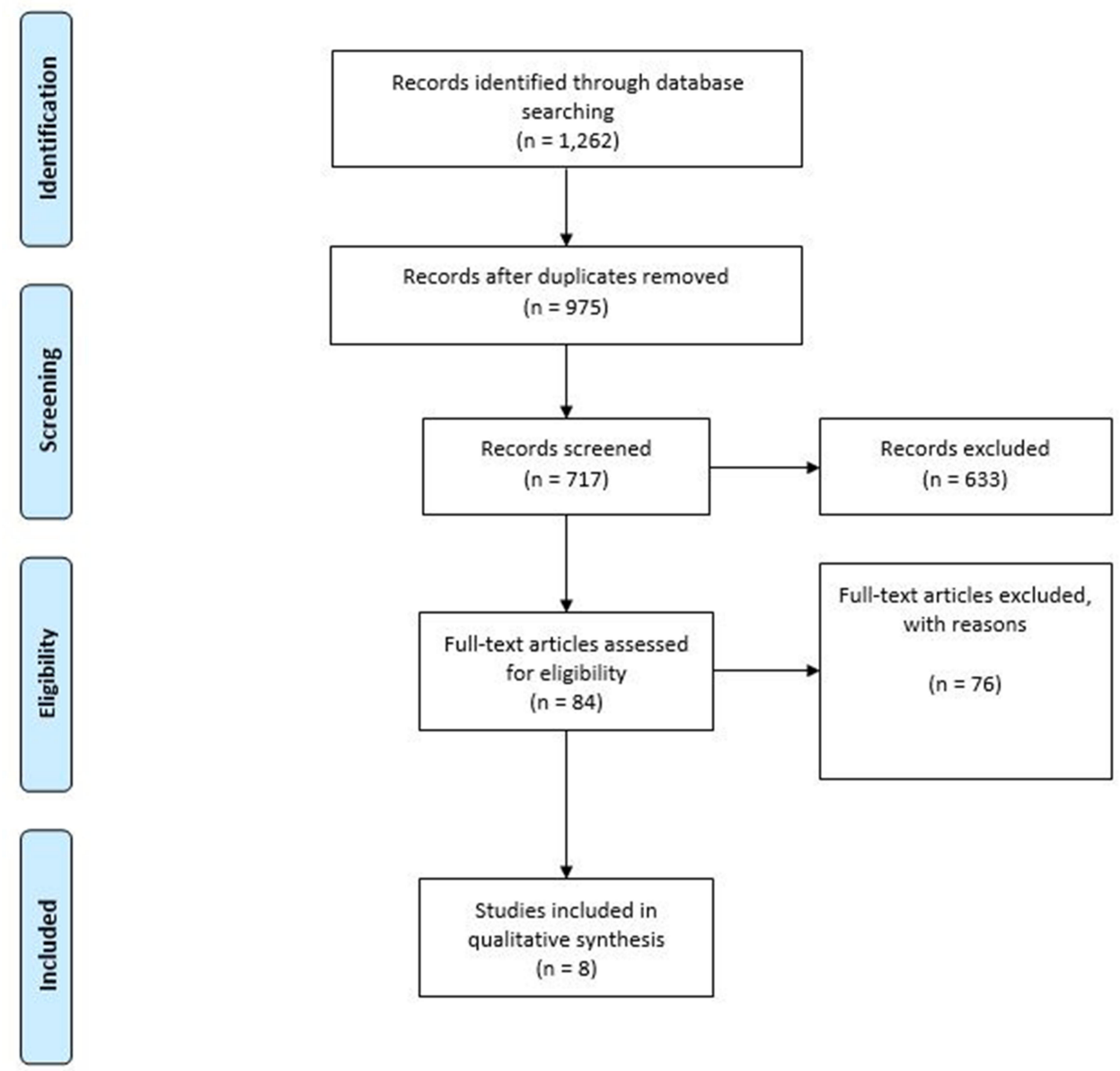

Figure I Prisma Flow Chart.

Note: Adapted from Moher D, Liberati A, Tetzlaff J, Altman DG. The PRISMA Group. Preferred reporting items for systematic reviews and meta-analyses: the PRISMA statement. PLoS Med. 2009;6(7):el000097. ${ }^{28}$

different technologies investigated. Out of the eight papers, one evidence referred to a Cochrane analysis on $\mathrm{CSTD} ;{ }^{29}$ papers focused the attention on the implementation of closed system devices in the preparation phase or in the administration phase, ${ }^{9,10,30,31}$ and three papers considered the benefits related to the adoption of a traceable workflow, based on gravimetric control. ${ }^{16,17,32}$

The literature review revealed the lack of scientific evidence concerning the head-to-head comparisons among the four scenarios under assessment, in terms of safety and efficacy. The articles included in the analysis presented reliable data assessed, even if they should be interpreted with caution. The implementation of ROBIN-I tool declared that none of the studies were at critical risk, due to selection bias (both the CSTDs and the control group were clearly identified), missing data, and preliminary results. In contrast, there was insufficient information to assess the risk of confounding bias in all the studies selected, as well as most studies did not report whether the training periods and other co-interventions were similar in both groups. It should be noted that all studies were at serious risk of bias in regard to the measurement of the outcomes, since none of the studies

Table I Safety and Efficacy Indicators, Derived from Literature Evidence

\begin{tabular}{|l|l|l|l|l|l|}
\hline Safety Indicator & Scenario 0 & Scenario I & Scenario 2 & Scenario 3 & P-value \\
\hline $\begin{array}{l}\text { Surface contamination } \\
\text { Efficacy Indicator } \\
\text { Identification errors }^{16}\end{array}$ & $26.39 \%$ & $12.24 \%$ & $12.24 \%$ & $12.24 \%$ & 0.0001 \\
\hline
\end{tabular}




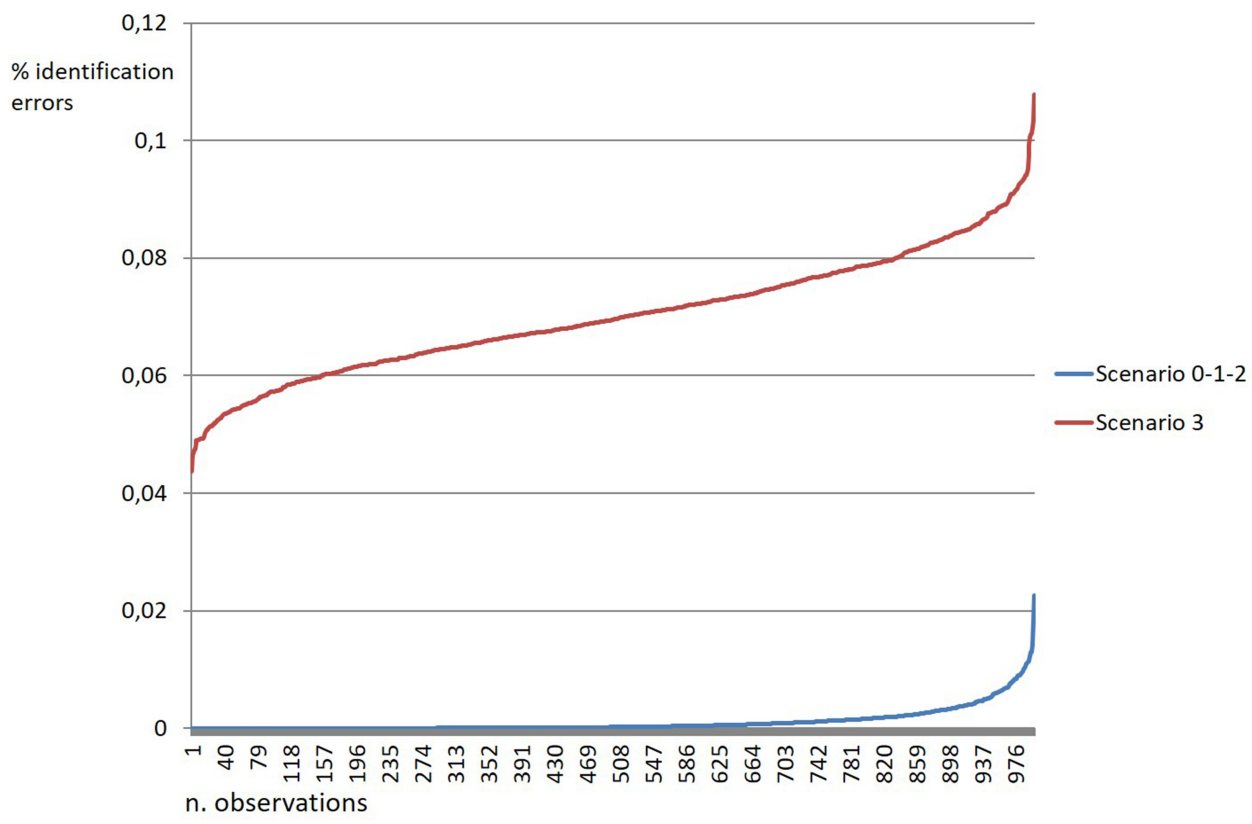

Figure 2 Beta distributions for the efficacy indicator.

used blinded assessment of outcomes. On the other hand, the implementation of Newcastle-Ottawa Scale, in the analysis related to the selection of the study groups, the comparability of the groups and the ascertainment of either the exposure or outcome of interest for case-control or cohort studies, reported that the risk of bias was not high. The control group was chosen in an interesting manner, and the outcomes measurement proved to be relevant in most cases, and both positive and negative outcomes were determined.

Despite no firm conclusions being drawn with regard to the effect of the implementation of closed-system medical devices, literature evidence (Table 1) depicts that CSTDs and traceable workflow introduction could: i) decrease surface $(12.24 \%$ vs $26.39 \%, P<0.0001)$ contamination ${ }^{30}$ and ii) improve the capability to identify dosage errors (7\% vs $0.096 \%, P<0.0001) .{ }^{17}$

Due to the above uncertainty on the results from literature evidence, the sensitivity analysis performed on the efficacy profile of the investigated medical devices (ie, capability of the panel of technologies to improve the identification of errors) always revealed a superior efficacy indicator of Scenario 3, with respect to the other investigated scenarios (Figure 2).

\section{Results from the Economic and Organizational Dimensions}

The total cost related to a single process (ie, preparation and administration activity) is detailed in Table 2. Specific information with regard to the different healthcare items of expenditure could be found in Supplementary Table 1. Despite no statistically significant differences emerging between the four scenarios under assessment (Scenario 0: $€ 36.21$ vs Scenario 1: $€ 36.24$ vs Scenario 2: €35.12 vs Scenario 3: €37.52, Pvalue $>0.05$ ), the panel of advanced technologies presented the best trade-off between cost sustained and efficacy gained, thus representing the preferable technology.

Figure 3 demonstrates that Scenario 2 would allow an economic optimization in $80 \%$ of cases, with a related

Table 2 Economic Evaluation and Cost-Efficacy Analysis

\begin{tabular}{|c|c|c|c|c|c|}
\hline & Preparation Phase & Administration Phase & Total Cost for the Process & $\begin{array}{l}\text { Efficacy } \\
\text { (\% Identification Errors) }\end{array}$ & CEV \\
\hline Scenario 0 & $€ 24.64$ & $€|| .57$ & $€ 36.21$ & $0.096 \%$ & $37,722.00$ \\
\hline Scenario I & $€ 24.67$ & $€ । \mid .57$ & $€ 36.24$ & $0.096 \%$ & $37,753.62$ \\
\hline Scenario 2 & $€ 24.67$ & $€ 10.45$ & $€ 35.12$ & $0.096 \%$ & $36,586.37$ \\
\hline Scenario 3 & $€ 25.04$ & $€ \mid 2.48$ & $€ 37.52$ & $7.000 \%$ & 535.96 \\
\hline
\end{tabular}




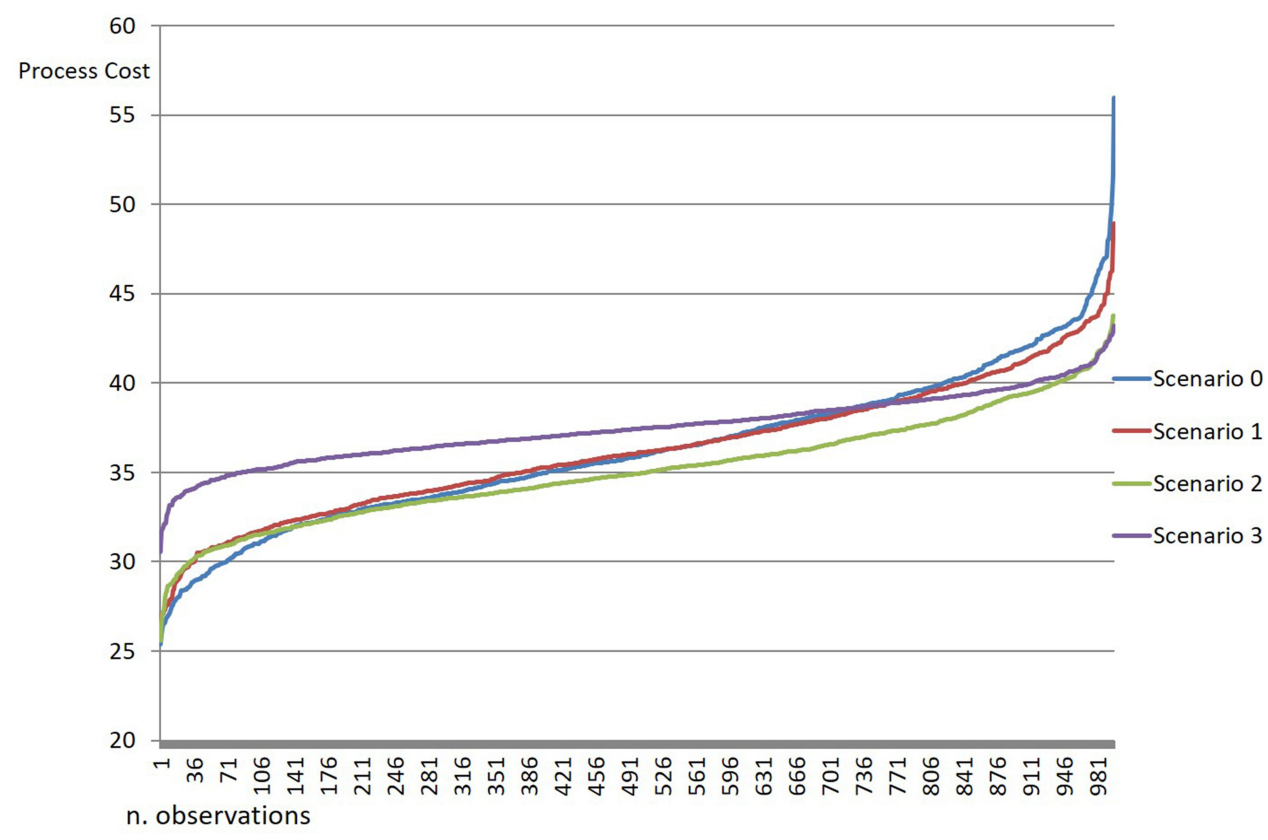

Figure 3 Gamma distributions for the process cost.

increase in the safety profile for healthcare workers, reducing the hazardous drugs risk. Despite the need of investment in more expensive technology for Scenario 3, sensitivity analysis reports that the innovative panel of advanced technology could present a probability to absorb lower economic resources equal to $28 \%, 23 \%$, and $3 \%$ in comparison with Scenario 0, Scenario 1, and Scenario 2, respectively, considering a 12-month time horizon.

A further sensitivity analysis was conducted with regard to the process cost, without considering the human resources absorption. Figure 4 reports that Scenario 2 presents a probability equal to $60 \%$ to absorb

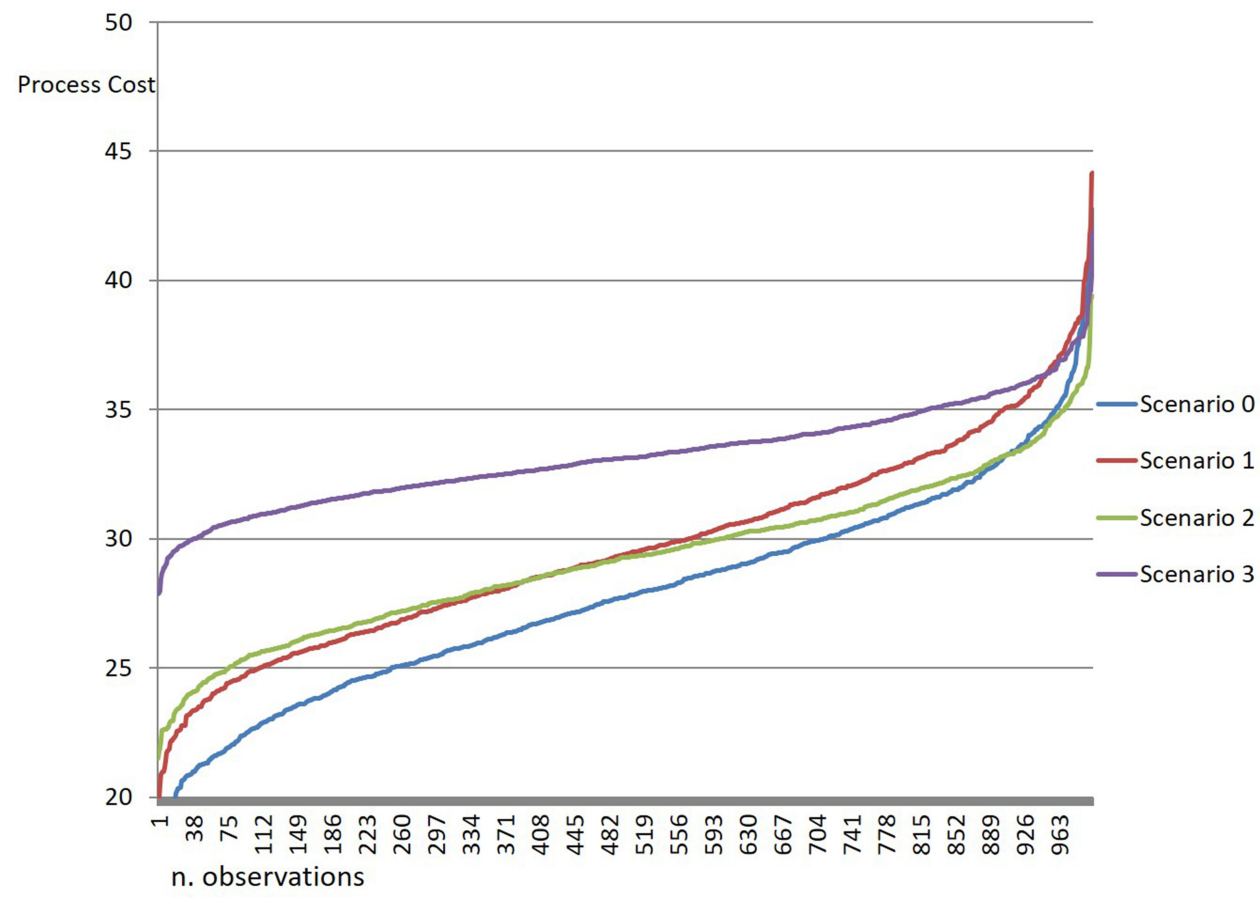

Figure 4 Gamma distributions for the process cost, without considering the costs related to human resources. 
Table 3 Budget Impact Analysis

\begin{tabular}{|c|c|c|c|c|}
\hline $\begin{array}{l}\text { Budget Impact } \\
\text { Analysis, } \\
\text { Considering a } \\
\text { Technology } \\
\text { Replacement } \\
\text { Rate Equal to } \\
100 \%\end{array}$ & \multicolumn{2}{|l|}{ Total Cost } & \multicolumn{2}{|c|}{ Variation in $€(\%)$} \\
\hline Scenario 0 & $€ 1,001,655$ & & & \\
\hline Scenario I & $€ I, 002,495$ & $\begin{array}{l}€ 840 \\
(+0.08 \%)\end{array}$ & & \\
\hline Scenario 2 & $€ 97 /, 500$ & $\begin{array}{l}- \\
€ 30,155 \\
(-3.01 \%)\end{array}$ & $\begin{array}{l}- \\
€ 30,995 \\
(-3.09 \%)\end{array}$ & \\
\hline Scenario 3 & $€ I, 037,726$ & $\begin{array}{l}€ 36,07 \mid \\
(+3.60 \%)\end{array}$ & $\begin{array}{l}€ 35,232 \\
(+3.51 \%)\end{array}$ & $\begin{array}{l}€ 66,226 \\
(+6.82 \%)\end{array}$ \\
\hline $\begin{array}{l}\text { Budget Impact } \\
\text { Analysis, } \\
\text { Considering a } \\
\text { Technology } \\
\text { Replacement } \\
\text { Rate Equal to } \\
75 \%\end{array}$ & \multicolumn{2}{|l|}{ Total Cost } & \multicolumn{2}{|c|}{ Variation in $€(\%)$} \\
\hline Scenario 0 & $€ 1,001,655$ & & & \\
\hline Scenario I & $€ 1,002,285$ & $\begin{array}{l}€ 630 \\
(+0.06 \%)\end{array}$ & & \\
\hline Scenario 2 & $€ 979,249$ & $\begin{array}{l}- \\
€ 22,406 \\
(-2.24 \%)\end{array}$ & $\begin{array}{l}- \\
€ 23,036 \\
(-2.30 \%)\end{array}$ & \\
\hline Scenario 3 & $€ 1,021,170$ & $\begin{array}{l}€ 19,515 \\
(+1.95 \%)\end{array}$ & $\begin{array}{l}€ \mid 8,885 \\
(+\mid .88 \%)\end{array}$ & $\begin{array}{l}€ 4 I, 92 I \\
(+4.28 \%)\end{array}$ \\
\hline
\end{tabular}

lower economic resources than Scenario 1. On the other hand, Scenario 3 is always related to higher costs with respect to the comparators, because of the use of the

Table 4 Time Required for the Preparation and the Administration Phases

\begin{tabular}{|l|l|l|l|}
\hline & $\begin{array}{l}\text { Preparation } \\
\text { Phase } \\
\text { (minutes) }\end{array}$ & $\begin{array}{l}\text { Administration } \\
\text { Phase (minutes) }\end{array}$ & $\begin{array}{l}\text { Total } \\
\text { (minutes) }\end{array}$ \\
\hline Scenario 0 & 7.001 & 2.005 & 9.006 \\
Scenario I & 4008 & 2.005 & 6.013 \\
Scenario 2 & 4.008 & 1.005 & 5.013 \\
Scenario 3 & 4.004 & 1.005 & 5.009 \\
\hline P-value & 0.002 \\
\hline
\end{tabular}

traceable workflow. This demonstrated that, except for the cost for innovative technologies acquisition, the factor having the major impact on the process cost, is related to the time spent by human resources for both preparation and administration activities conduction.

The BIA (Table 3 ) indicates that the adoption of one or more advanced technologies, moving from one scenario to another one, would generate significant economic savings for the hospitals providing these services, with a better safety and efficacy profile. No economic constraints could suggest the hospitals' managers to not introduce CSTDs. Focusing only on the last Scenario, which involves the traceable workflow implementation, integrating the closed systems of preparation and administration, hospitals would require an additional investment of $3.51 \%$ (if compared to Scenario 1) and of $+6.82 \%$ (if compared to Scenario 2 ), both in case of technological replacement rate equal to $100 \%$ and equal to $75 \%$ (in this last case, with a contraction in the economic impact: only $+4.28 \%$ of additional economic resources, in the comparison between Scenario 3 and Scenario 2).

From an organizational point of view, the time spent by the healthcare professionals for a single drug prepared and administered was defined (Table 4), thus reporting a significant decrease within Scenario 3.

Gamma distribution for organizational issues confirmed the "time-saving" nature of the advanced panel of technologies (Figure 5). Scenario 3 presented a probability of 99\%, $98 \%$, and $65 \%$, respectively, to require less time in performing both the preparation and the administration activities, comparing Scenario 0, Scenario 1, and Scenario 2.

From a hospital system-capacity point of view, Table 5 reveals that the presence of CSTD in the preparation phase, the presence of closed systems in the administration phase, and the presence of a traceable workflow, generates organizational savings equal to $1,842 / 1,843$ hours (255 working days for a healthcare professional).

\section{Discussion}

Professional exposure to chemotherapy and other hazardous drugs during preparation and administration has been a concern for more than 30 years. ${ }^{33}$ Several steps in the compounding anticancer drugs create working conditions that may allow the drugs' escape both into the compounding room, as well as into the work surface: preventing workplace contamination is the best strategy to minimize cytotoxic drug exposure, an advantage to the healthcare providers. 


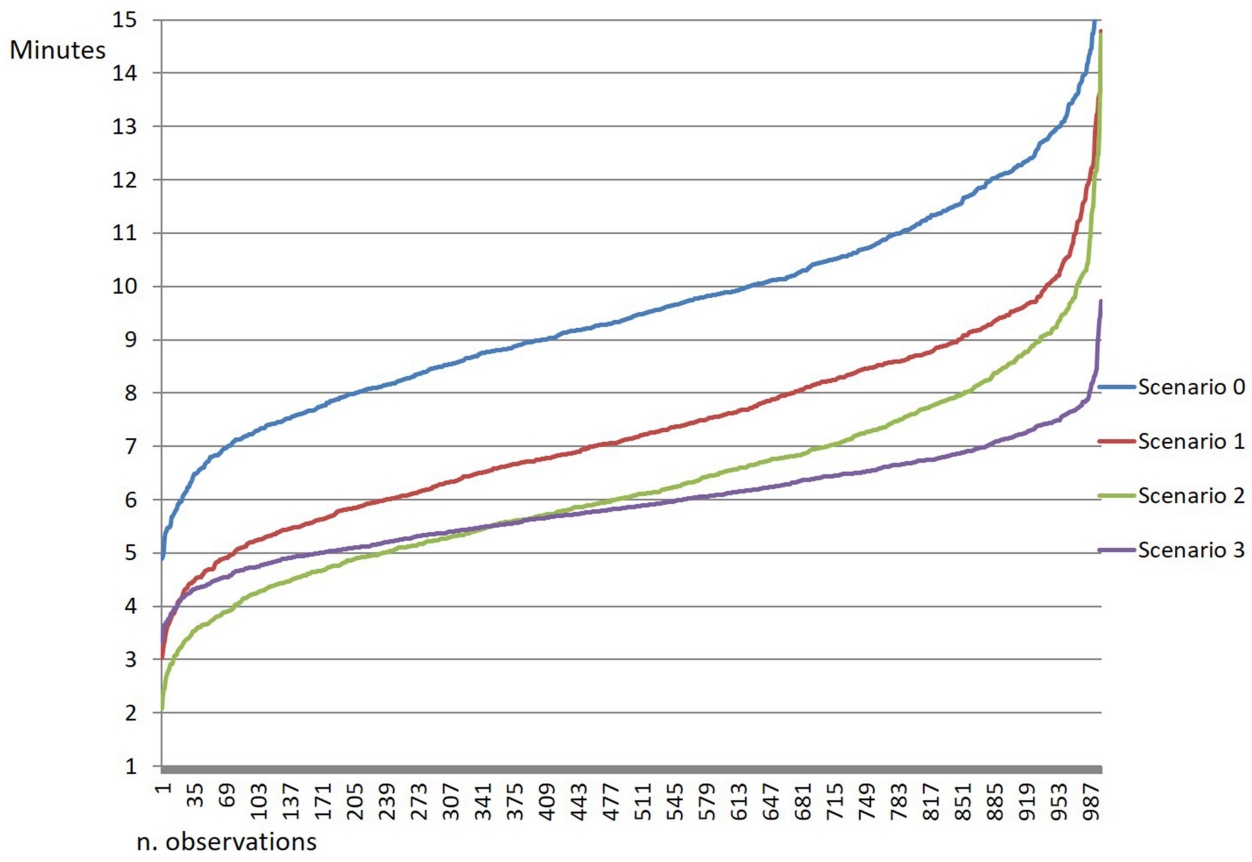

Figure 5 Gamma distributions for the time spent for the preparation and administration phase.

In this view, closed-system transfer devices, used in the preparation and in the administration phase, play an increasing role in many healthcare systems, as part of an overall approach to reduce occupational exposure to chemotherapeutic agents, to be used together with ventilated cabinets and proper personal protective equipment.

Despite the adoption of a closed-system in the preparation and administration of chemotherapeutic agents being regulated by both European and Italian laws, no clear evidence exists with regard to the hospital's benefits in adopting such technologies, in particular with reference to the possibility to integrate the preparation phase with a traceable workflow using gravimetric control. ${ }^{17}$

The results of the study show that the introduction of advanced technologies devoted to the preparation and administration of chemotherapeutic drugs may be considered valid technological alternatives within the investigated setting, despite the need of further comparative studies useful to retrieve more robust evidence-based results, covering all the different typologies of chemotherapeutic agents. The strategic relevance of the topic is also supported by the presence of a Cochrane review on CSTDs in the preparation phase. ${ }^{29}$

Despite the presence of a medium-quality scientific evidence, because of the presence of a low-risk of bias derived from ROBIN-I tool and the Newcastle-Ottawa Scale, important strengths are found in the safety and in the efficacy dimensions, in terms of a decrease in the professional exposure and increase in the identification errors, thus achieving the two-fold objective of cancer care. Why are closed systems not implemented in the routine clinical practices? Is it an economic problem? The study demonstrated a process economic advantage in the closed systems introduction (both in the preparation and in the administration phase - Scenario 2), and an investment only in the case of traceable workflow implementation. This economic result could be appreciated as an advantage only if the attention of the reader is not focused on the CSTDs acquisition cost, that are commonly higher than open systems, but on the analysis of the entire preparation and administration process cost. According to the above, the present study tried to overcome the budget silo mentality, by economically evaluating all the different healthcare items of costs, in order to understand the real impact of CSTDs implementation in a hospital organization, and the related technological change. In this view the adoption of Scenario 3 was related to the marginal incremental costs required for the introduction of advanced technologies, that could be absorbed already in the first year after their introduction, especially with reference to the possibility of freeing-up human resources. This is particularly relevant in the specific preparation phase, according to a gravimetric control approach, replacing 
Table 5 The Definition of System Capacity

\begin{tabular}{|c|c|c|c|c|}
\hline $\begin{array}{l}\text { System Capacity, } \\
\text { Considering a } \\
\text { Technology } \\
\text { Replacement Rate } \\
\text { Equal to } 100 \%\end{array}$ & Hours & \multicolumn{3}{|c|}{ Variation in Hours (\%) } \\
\hline Scenario 0 & 4,152 & & & \\
\hline Scenario I & 2,772 & $\begin{array}{l}-1,380 \\
(-33 \%)\end{array}$ & & \\
\hline Scenario 2 & 2,311 & $\begin{array}{l}-|, 84| \\
(-44 \%)\end{array}$ & $\begin{array}{l}-46 \mid \\
(-17 \%)\end{array}$ & \\
\hline Scenario 3 & 2,309 & $\begin{array}{l}-1,843 \\
(-44 \%)\end{array}$ & $\begin{array}{l}-463 \\
(-17 \%)\end{array}$ & $\begin{array}{l}-2 \\
(-0.1 \%)\end{array}$ \\
\hline \multicolumn{5}{|l|}{$\begin{array}{l}\text { System Capacity, } \\
\text { Considering a } \\
\text { Technology } \\
\text { Replacement Rate } \\
\text { Equal to } 75 \%\end{array}$} \\
\hline Scenario 0 & 4,152 & & & \\
\hline Scenario I & 3,117 & $\begin{array}{l}-1,035 \\
(-25 \%)\end{array}$ & & \\
\hline Scenario 2 & 2,426 & $\begin{array}{l}-1,727 \\
(-42 \%)\end{array}$ & $\begin{array}{l}-691 \\
(-22 \%)\end{array}$ & \\
\hline Scenario 3 & 2,310 & $\begin{array}{l}-1,842 \\
(-44 \%)\end{array}$ & $\begin{array}{l}-807 \\
(-26 \%)\end{array}$ & $\begin{array}{l}-117 \\
(-5 \%)\end{array}$ \\
\hline
\end{tabular}

the visual control of drug dosage (usually performed by two healthcare professionals).

Considering a technological replacement rate equal to $100 \%$ and comparing Scenario 3 with Scenario 0, hospitals would benefit from an organizational saving equal to 1,842 / 1,843 healthcare professionals' working hours, despite the marginal costs incrementation equal to $3 \%$ on average, particularly due to the purchase of the most expensive medical devices. Therefore, the economic analysis presented in the study could be considered a sort of worst-case scenario, since it did not consider the cost of the drug prepared and administered, in particular with regard to the possibility to reduce the drug waste. Scientific literature on the topic indicated that the use of CSTD in the preparation phase would maintain the sterility of the drug up to 7 days, ${ }^{12-14}$ which would reduce drug waste by $51.35 \%$, with a consequent economic annual saving of $€ 619,318$. $^{31}$

The multi-dimensional approach conducted has demonstrated the possibility to pursue a better quality of healthcare processes, together with higher levels of safety, with regard to a reduction in surface and healthcare professionals' contamination.

The above advantages and strengths could also be helpful both in the procurement process, to create one or more ad hoc tender to the oncologic pathways, and in the choice of the externalized drugs' compounding services (for hospital seeking for an external supply for this specific activity, thus preferring laboratories, acting as outsourced suppliers, using CSTDs). According to the aforementioned consideration, the results of the study have paved the way to the development of further research activities, that is the definition of the correct requirement and quantities of the different medical devices used in the preparation and in the administration phase, to be purchased for the right care of the population, within specific settings. This could be useful for the creation of a specific set of medical devices to be used during the preparation and the administration of chemotherapy agents, thus supporting the production of the most appropriate batch tenders.

In conclusion, results demonstrate the strategic relevance related to the introduction of advanced technologies into the Italian clinical practice, its economic sustainability and feasibility, as well as the potentialities in process improvement, with important benefits for hospitals, thus being consistent with the EU recommendation on the topic (Carcinogens and Mutagens Directive 2004/37/EC -CMD-). ${ }^{6}$

\section{Abbreviations}

$\mathrm{ABC}$, activity based costing; BIA, budget impact analysis; CEA, cost-effectiveness analysis; CSTD, closed-system transfer device; HTA, health technology assessment.

\section{Acknowledgments}

The authors would like to thank all the professionals involved, for their valuable support to complete the qualitative and quantitative questionnaires, leading to the success of the present research activity.

\section{Author Contributions}

All authors made substantial contributions to the conception and design, acquisition of data, or analysis and interpretation of data; took part in drafting the article or revising it critically for important intellectual content; agreed to submit to the current journal; gave final approval of the version to be published; and agree to be accountable for all aspects of the work. 


\section{Funding}

There is no funding to report.

\section{Disclosure}

Emanuele Porazzi reports personal fees from Università Cattaneo - LIUC, outside the submitted work. Emanuela Foglia reports personal fees from Smith \& Nephew Srl, Johnson \& Johnson Medical SpA, Astellas Pharma SpA, and BD, outside the submitted work. The authors report no other potential conflicts of interest in this work.

\section{References}

1. Negrão Carvalho R, Randi G, Giusti F, et al. Socio-economic regional microscope series. Cancer burden indicators in Europe: insights from national and regional information; 2018. Available from: https:// publications.jrc.ec.europa.eu/repository/bitstream/JRC111731/ kjbf18204enn.pdf. Accessed November 11, 2020.

2. Corrie PG. Cytotoxic chemotherapy: clinical aspects. Medicine. 2008;36(1):24-28. doi:10.1016/j.mpmed.2007.10.012

3. Hon CY, Teschke K, Demers PA, Venners S. Antineoplastic drug contamination on the hands of employees working throughout the hospital medication system. Ann Occup Hyg. 2014;58(6):761-777.

4. Graeve CU, McGovern PM, Alexander B, et al. Occupational exposure to antineoplastic agents: an analysis of health care workers and their environments. Workplace Health Saf. 2017;65(1):9-20. doi:10.1177/2165079916662660

5. Ratner PA, Spinelli JJ, Beking K, et al. Cancer incidence and adverse pregnancy outcome in registered nurses potentially exposed to antineoplastic drugs. BMC Nurs. 2010;9:15. doi:10.1186/1472-6955-9-15

6. EU (Council of the European Union). Council Directive 90/394/EEC of 28 June 1990 on the protection of workers from the risks related to exposure to carcinogens at work (Sixth individual Directive within the meaning of Article 16 (1) of Directive 89/391/EEC). [Internet]; 1990. Available from: http://eur-lex.europa.eu/legal-content/EN/ TXT/?uri=CELEX:31990L0394. Accessed December 14, 2014.

7. NIOSH. NIOSH Alert: preventing occupational exposures to antineoplastic and other hazardous drugs in health care settings. Cincinnati, OH: U.S. Department of Health and Human Services, Centers for Disease Control and Prevention, National Institute for Occupational Safety and Health, DHHS (NIOSH) Publication No. 2004-165. Available from: https://www.cdc.gov/niosh/docs/2004-165/pdfs/2004 165.pdf. Accessed Nov 18, 2020.

8. Siderov J, Kirsa J, McLauchlan R. Reducing workplace cytotoxic surface contamination using a closed-system transfer device. J Oncol Pharm Pract. 2010;16:19-25. doi:10.1177/1078155209352543

9. Sessink PJ, Connor TH, Jorgenson JA, Tyler TG. Reduction in surface contamination with antineoplastic drugs in 22 hospital pharmacies in the US following implementation of a closed-system drug transfer device. J Oncol Pharm Pract. 2011;17(1):39-48. doi:10.1177/1078155210361431

10. Clark BA, Sessink PJM. Use of a closed system drug-transfer device eliminates surface contamination with antineoplastic agents. J Oncol Pharm Pract. 2013;19:99-104. doi:10.1177/10781552124 68367

11. Yoshida J, Tei G, Mochizuki C, et al. Use of a closed system device to reduce occupational contamination and exposure to antineoplastic drugs in the hospital work environment. Ann Occup Hyg. 2009;53(2):153-160.

12. Carey ET, Forrey RA, Haughs D. Second look at utilization of a closed-system transfer device (PhaSeal). Am J Pharm Benefits. 2011;3(6):311-318.
13. De Prijck K, D’Haese E, Vandenbroucke J, et al. Microbiological challenge of four protective devices for the reconstitution of cytotoxic agents. Lett Appl Microbiol. 2008;47(6):543-548. doi:10.1111/ j.1472-765X.2008.02463.x

14. McMichael DM, Jefferson DM, Carey T, et al. Utility of the PhaSeal closed system drug transfer device. Am J Pharm Benefits. 2011;3 (1):9-16

15. Terkola R, Czejka M, Bérubé J. Evaluation of real-time data obtained from gravimetric preparation of antineoplastic agents shows medication errors with possible critical therapeutic impact: results of a large-scale, multicentre, multinational, retrospective study. J Clin Pharm Ther. 2017;42(4):446-453. doi:10.1111/ jcpt. 12529

16. Prusch AE, Suess TM, Paoletti RD, Olin ST, Watts SD. Integrating technology to improve medication administration. Am J Health Syst Pharm. 2011;68(9):835-842. doi:10.2146/ajhp100211

17. Reece KM, Lozano MA, Roux R, Spivey SM. Implementation and evaluation of a gravimetric i.v. workflow software system in an oncology ambulatory care pharmacy. Am J Health Syst Pharm. 2016;73(3):165-173. doi:10.2146/ajhp150169

18. Balick R. APhA resource helps pharmacist advocacy efforts. Patient Saf. 2016;22(7):486.

19. SIFO. Gestione del rischio di esposizione del personale sanitario nella manipolazione dei farmaci antineoplastici iniettabili: gli aspetti di prevenzione e la caratterizzazione delle misure di sicurezza; 2017. Available from: https://www.sifoweb.it/images/pdf/atti vita/attivita-scientifica/aree_scientifiche/area_oncologica/ CONSENSUS_DOCUMENT_FINALE.pdf. Accessed November 11, 2020.

20. Sampietro-Colom L, Lach K, Cicchetti A, et al. The AdHopHTA handbook: a handbook of hospital-based Health Technology Assessment (HB-HTA); public deliverable; the AdHopHTA Project (FP7/2007-13 grant agreement nr 305018); 2015. Available from: http://www.adhophta.eu/handbook. Accessed November 11, 2020.

21. Stern JAC, Herńan MA, Reeves BC, et al. ROBINS-I: a tool for assessing risk of bias in non-randomised studies of intervention. BMJ. 2016;355:i4919. doi:10.1136/bmj.i4919

22. Wells GA, Shea B, O'Connell D, et al. The Newcastle-Ottawa Scale (NOS) for assessing the quality of non-randomized studies in metaanalysis; 2000. Available from: http://www.ohri.ca/programs/clini cal_epidemiology/oxford.asp. Accessed November 11, 2020.

23. Bubbio A. Calcolo dei costi per attività, Activity Based Costing. Milano: Guerini e Associati; 2002.

24. Mauskopf JA, Sullivan SD, Annemans L, et al. Principles of good practice for budget impact analysis: report of the ISPOR Task Force on good research practices-budget impact analysis. Value Health. 2007;10(5):336-347. doi:10.1111/j.1524-4733.2007.00 187.x

25. Sullivan SD, Mauskopf JA, Augustovski F, et al. Budget impact analysis-principles of good practice: report of the ISPOR 2012 budget impact analysis good practice II task force. Value Health. 2014;17 (1):5-14. doi:10.1016/j.jval.2013.08.2291

26. Spiegelhalter DJ, Myles JP, Abrams KR. Bayesian Approaches to Clinical Trials and Health-Care Evaluation. N.Y: Wiley; 2003.

27. Bernardo JM, Smith AFM. Bayesian Theory. West Sussex, England: John Wiley \& Sons Ltd; 1994.

28. Moher D, Liberati A, Tetzlaff J, Altman DG; The PRISMA Group. Preferred reporting items for systematic reviews and meta-analyses: the PRISMA statement. PLoS Med. 2009;6(7):e1000097. doi:10.1371/journal.pmed.1000097

29. Gurusamy KS, Best LMJ, Tanguay C, Lennan E, Korva M, Bussières JF. Closed-system drug-transfer devices plus safe handling of hazardous drugs versus safe handling alone for reducing exposure to infusional hazardous drugs in healthcare staff. Cochrane Database Syst Rev. 2018;(3):CD012860. 
30. Simon N, Vasseur M, Pinturaud M, et al. Effectiveness of a closedsystem transfer device in reducing surface contamination in a new antineoplastic drug- compounding unit: a prospective, controlled, parallel study. PLoS One. 2016;11(7):e0159052. doi:10.1371/journal.pone.0159052

31. Edwards MS, Solimando DA, Grollman FR, et al. Cost savings realized by use of the PhaSeal $\left({ }^{\circledR}\right)$ closed-system transfer device for preparation of antineoplastic agents. J Oncol Pharm Pract. 2013;19 (4):338-347. doi:10.1177/1078155213499387
32. Franklin BD, O' Grady K, Donyai P, et al. The impact of a closedloop electronic prescribing and administration system on prescribing errors, administration errors and staff time: a before-and-after study. Qual Saf Health Care. 2007;16:279-284. doi:10.1136/ qshc.2006.019497

33. Power LA, Polovich M. Safe handling of hazardous drugs: reviewing standards for worker protection. Pharm Pract. 2012;31-42.

\section{Publish your work in this journal}

ClinicoEconomics and Outcomes Research is an international, peerreviewed open-access journal focusing on Health Technology Assessment, Pharmacoeconomics and Outcomes Research in the areas of diagnosis, medical devices, and clinical, surgical and pharmacological intervention. The economic impact of health policy and health systems organization also constitute important areas of coverage. The manuscript management system is completely online and includes a very quick and fair peer-review system, which is all easy to use. Visit http://www.dovepress.com/testimonials.php to read real quotes from published authors. 